\title{
Using practical philosophy to enhance the self- regulation of children in secure accommodation
}

\section{Gavin Heron}

Lecturer School of Social Work \& Social Policy, Faculty of Humanities \& Social Sciences, University of Strathclyde, 141 St James Road, Glasgow G4

0LT Scotland

01414448644

ORCID 0000-0002-2238-1532

gavin.heron@strath.ac.uk

\section{Claire Cassidy}

Senior Lecturer School of Education, Faculty of Humanities \& Social Sciences,

University of Strathclyde, 141 St James Road, Glasgow G4 0LT Scotland

ORCID 0000-0002-3088-1721

claire.cassidy@strath.ac.uk 


\title{
Using practical philosophy to enhance the self-regulation of children in secure accommodation
}

\begin{abstract}
Secure accommodation provides extreme forms of control and support for a small minority of society's most vulnerable children. Within such environments it is unclear how children exhibit or develop self-regulation when external controls affect every aspect of day-to-day life. This study provides an insight into self-regulation by examining children's adherence to the rules associated with a practical form of philosophy, namely Community of Philosophical Inquiry (CoPI). Data was collected from a series of CoPI sessions which took place in secure accommodation and a thematic analysis was used to identify key themes emerging from participants' rule-adherence. The findings suggest that argumentative dialogue allows children to demonstrate self-regulation in relation to the CoPI rules, although it is often sporadic and variable between individuals. Whilst encouraging argumentation and dialogue can seem counterintuitive, it might promote more adaptive behaviours, which will give children in secure accommodation greater control over their lives.
\end{abstract}

Keywords: secure accommodation; self-regulation; behavioural difficulties; Philosophy with Children 


\section{Introduction}

The importance of self-regulation within our lives is widely recognised, yet this aspect of human development specific to children in secure accommodation has warranted little attention in education and social work literature. This study used Community of Philosophical Inquiry (CoPI) within a secure setting in order to ascertain if the children would enjoy and be able to do practical philosophy. During the CoPI sessions it was apparent that the children's ability to adhere to the rules of CoPI and engage in the dialogue was variable and that this might be an indication of their ability to self-regulate their own behaviours. In order to explore this issue, the participants' CoPI dialogues were analysed in relation to their adherence to the rules of CoPI. CoPI is a practical form of philosophy and has been used effectively with various groups, including children in mainstream schools and those with Additional Support Needs such as autism and social, emotional and behavioural difficulties (Cassidy and Christie 2014). The originality of this study is in applying CoPI within a secure setting where external controls upon children limit even the most basic life choices, thereby leaving little scope to regulate their own behaviours. Furthermore, unlike previous studies using CoPI, which often focus on the philosophical dialogue, this study examines the rules integral to CoPI to explore the extent to which self-regulation can be demonstrated by children in one of the most controlled environments. If the participatory, argumentative and dialogic nature of CoPI can be shown to enhance self-regulation within secure settings, it might also have benefits for other social work and health services where vulnerable children require support. Rather than trying to quell arguments, enhancing selfregulation using argumentation and dialogue might help to promote more adaptive behaviours, including better reasoning and judgement, which can give highly vulnerable children greater control over their own lives. Such control is essential when children re-enter 
the community and are no longer subject to the external controls and containment imposed by the secure setting.

\section{Secure accommodation and self-regulation of children}

Secure accommodation (locked provision) for children who are under 18 years of age is the most controlling form of care and it has a dual purpose of rehabilitation of the children and protecting the public (Souverein, Van Der Helm, and Stams 2013). Across Europe and North America secure accommodation is known, for example, as juvenile detention centres, treatment centres and youth reformatories and the purpose of these institutions vary greatly in terms of rehabilitation, treatment and punishment (Hart 2015). To date, there remains ongoing controversy surrounding the role, outcomes and effectiveness of secure care as a form of intervention (Sinclair and Geraghty 2008; Roesch-Marsh 2012). There is, for example, growing concern over what is often referred to as 'deviancy training' whereby interventions (e.g. anti-social behaviour training) with adolescent peer groups inadvertently increase rates of problematic behaviour, especially in high-risk individuals (Dishion 1999). The reason for this deterioration in behaviour arises from repetition of contact between young people brought about by the intervention. There is also a gap in knowledge about what actually happens in many secure settings. In Scotland, where this study was undertaken, despite there being only five secure units (total of 90 beds), Moodie $(2015,2)$ notes that, 'there is currently an evidence gap with regards to both short term outcomes and longitudinal follow up of children leaving secure care'. In addition to an evidence gap, the experiences of children suggest there are considerable variations in the organisation, culture and structure of secure settings within any single country. The Children's Rights Director for England states that: 
Those who had been in more than one unit told us that each unit was run very differently. This was usually to do with the way different staff groups worked, what they allowed and what they didn't allow. It was also to do with whether most children were 'welfare' placements, or 'criminal' placements, and if the unit had both, how the mix worked out (Morgan 2009, 6).

The complex nature of secure environments and the multiplicity of factors, including cultural norms, hierarchies, and informal and formal peer cultures form the residential milieu and influence opportunities for the way self-regulation is demonstrated and understood.

The range of complex behaviours exhibited by children prior to admission to secure accommodation include: absconding; manipulation by others; misusing alcohol and illicit drugs; involvement in highly disruptive behaviours; unsafe sexual activity and being sexually exploited; self-harming; and offending (Bullock, Little, and Millham 1998; Roesch-Marsh 2014). Underlying their vulnerability and high risk behaviours are often acute problems with childhood attachment and experiences of trauma, which are recognised as having an adverse effect on a child's ability to self-regulate (Yen, Konold, and McDermott 2004). The child's adaptive behaviours are often typified as being out of control, which places the individual and/or others at serious risk. This suggests that the adaptive behaviours have limited the development of self-regulation. It seems plausible that enhancing self-regulation might therefore provide a means of allowing children to reduce problematic behaviours.

Self-regulation is viewed as an essential component of human development and integral to our ability to reason and make sound judgements. It is a complex concept and Bauer and Baumeister $(2011,65)$ provide a useful definition, whereby: 
self-regulation is the capacity to alter the self's responses to achieve a desired state or outcome that otherwise would not arise naturally... to interrupt the self's tendency to operate on automatic pilot and to steer behaviour consciously in a desired direction.

Baumeister and Vohs (2004) make the distinction between self-regulation and self-control, with the former incorporating goal-directed behaviour whereas the latter is concerned solely with impulse control. Any ability to self-regulate also depends on the choice available to individuals, their agency and sense of responsibility (Mowat 2010) and that the context is supportive, yet challenging (Boekaerts and Corno 2005).

Enhancing self-regulation in young people with social, emotional and behavioural difficulties is increasingly viewed as an important goal and Duckworth et al. (2009) identify a range of strategies and programmes aimed at enhancing children's self-regulation. These include developing children's emotions, awareness, responsibility, empathy, conflict resolution, compromise and co-operation. The interventions used to enhance self-regulation typically focus on children's specific behaviours (e.g. Mowat 2010) or changes to the curriculum (e.g. Smith 2017). The construct of 'self-regulatory strength' (Bauer and Baumeister 2011) provides a useful way to conceptualise the development of self-regulation. Self-regulation can be depleted and replenished after use, in the same way that a muscle can be strengthened with exercise. Research by DeWall et al. (2007) indicates that when self-regulation is depleted individuals are more prone to aggression when provoked. Strengthening and replenishing self-regulation might therefore, be a particularly useful strategy for minimising aggressive and disruptive behaviour in highly vulnerable children. As such, self-regulation should not be seen as a fixed entity, but rather a resource that changes within individuals and that alters over time (Muraven and Baumeister 2000). 
Despite the growing interest in self-regulation with young people who have emotional and behavioural difficulties there are key considerations for this study. For Khon (2008) the ability to regulate behaviour is context specific. Therefore, the way children think and behave while in secure accommodation may be very different from a community setting. In particular, children may be forced to adapt to certain rules and regulations in secure accommodation which are less relevant or applicable to community settings. Also, the compliance required by adults across a range of settings might be quite different from a child's genuine desire to self-regulate. The issue of compliance and control forms the basis of Vassallo's (2015) critique of the 'neutral' and 'value free' way in which self-regulation is presented in the literature. For Vassallo self-regulation reflects a neoliberal ideology, whereby institutions such as schools want to create manageable pupils rather than empowered and autonomous ones. As such, self-regulation reduces the need for authorities to govern directly because individuals self-govern in ways that meet the interests and aims of the institution, with little understanding of the way control and power are used to manipulate. Understanding the way in which control and power is mediated in specific contexts is complicated further by the lack of evidence of specific strategies intended to develop selfregulation for vulnerable children. Smith et al. $(2017,144)$ state that ' few, if any, current evidenced-based SR [self-regulation] intervention efforts provide substantive, comprehensive, and intensive instruction necessary for students who exhibit the most significant social-emotional and behavioural needs'. The complex nature of secure accommodation makes it difficult to identify, let alone control, the range of individual and institutional variables affecting the self-regulation of children undertaking a specific activity. 
The gaps in knowledge about the cultural contexts, normative goals and organisational demands of secure settings raise questions about whether self-regulation is desirable or whether such environments actually negate the need and opportunity for many children to regulate their own behaviour. Yet, without a growth in self-regulation while in secure accommodation, there is a greater risk of children becoming out-of-control on their release.

\section{Philosophy, rules and arguing}

The assumption in this study is that an adherence to the rules of Community of Philosophical Inquiry (CoPI) while engaging in argumentative dialogue will provide opportunities for children's self-regulation. Essentially, using CoPI to provide a forum in secure accommodation where children can argue might develop self-regulation, thereby reducing maladaptive behaviours. It is plausible that the rules associated with other activities such as games or sport might also be useful to understanding children's self-regulation, however, using argumentative dialogue and the rules of CoPI with children in secure accommodation seemed particularly relevant due to its highly structured format. Given the impulsive nature and lack of control exhibited by many children when admitted to secure accommodation, a strategy using argumentative dialogue could be personally meaningful, thereby enhancing children's participation and engagement in the CoPI sessions.

Rather than academic philosophy where participants learn about philosophers and/or their ideas, CoPI is an approach to practical philosophy that engages participants in facilitated, structured philosophical dialogue within a group setting (McCall 2009). The cooperative and argumentative dialogue can only exist with adherence to certain rules, which allows participants to demonstrate self-regulation. 
Using CoPI as a method to investigate self-regulation seems appropriate because it requires a participatory approach where individuals, rather than the researcher or facilitator of the dialogue, is in control of the philosophical dialogue. A question, generated by one of the participants, is used to initiate the dialogue with the intention of encouraging a shared search for meaning through the dialogue (Cassidy 2012). Questions are far-reaching, relating to, for example, the nature of reality, knowledge, justice, a meaningful life, or what makes something art. CoPI is not a method of intervention for addressing problematic behaviours and, unlike most 'deviancy training', it is used in mainstream schools and with children who have a range of academic abilities. The rules for CoPI are designed to ensure the most fruitful philosophical dialogue and require participants to adhere to the order of speaking as directed by the facilitator. The CoPI rules are as follows:

- Participants sit in a circle in order to see one another, with the facilitator outside the circle.

- A stimulus is presented and questions arising from this are posed by the participants. These are noted verbatim by the facilitator.

- The facilitator selects the question for the dialogue and asks the person who posed the question to say something about the question, either what is puzzling about it or to begin addressing the question directly.

- When participants wish to contribute they must raise their hand and wait to be called by the facilitator.

- When participants speak they must agree/disagree with at least one previous speaker and give reasons for their agreement/disagreement using the format: 'I agree with [person's name] because...'

- Participants are not allowed to use technical language or jargon. 
- Participants may not refer to an authority such as a teacher, a television programme, a book, and the like, for their reasons.

- Participants need not offer their own opinions.

- There is no search for a conclusion or consensus at the end of the dialogue.

The role of the facilitator within CoPI is to encourage individuals to participate and adopt greater responsibility for their learning. Within CoPI the facilitator selects the speakers in an order that will juxtapose perspectives likely to be offered and beyond this the facilitator only intervenes in order to seek clarification; she does not contribute to the content of the dialogue (Cassidy 2012). A dialogue requires participants to argue, and in doing so, they have to agree and/or disagree with at least one previous speaker and provide their justification for that agreement/disagreement. Participants need not offer their own personally held opinions; they can experiment with ideas. This process of arguing requires judgement and control over feelings, especially when participants are frustrated, excited or angry. All participants are welcome to contribute to the dialogue, although no individual is forced to speak. In order to create a more equal platform where no-one is seen to have greater expertise than anyone else and to ensure that everything remains open to question, participants may not use technical language, jargon or refer to an authority such as a newspaper, book or another person for their justifications (Cassidy and Christie 2014).

\section{Method}

A case study approach can provide researchers with in-depth insights into participants' lived experiences within a specific context (Bassey 1999). This enables the researchers to access a 
single institution and focus on depth of understanding about an issue that had not been previously explored (Miles and Huberman 1994). For this study, the case study approach provides a unique insight into self-regulation by examining participants' rule-adherence when doing CoPI within a classroom setting. However, the case study is limited and narrowly focused in that it cannot encapsulate or consider the wide range of variables and influences that might affect a participant's behaviour prior to or during the sessions. Essentially, the case study is used to provide a 'snapshot' of a group activity with participants whose attendance varied across 10 CoPI sessions.

The researchers negotiated with the manager in a secure unit in Scotland to undertake a series of CoPI sessions with children and staff. In a departure from existing research, this study focused on the rules integral to CoPI rather than the content of the philosophical dialogue. The research questions were:

1. does adherence to the rules of CoPI provide insight into the self-regulation of highly vulnerable children living in a secure setting?

2. to what extent does the argumentative dialogue within CoPI encourage and/or develop self-regulation for vulnerable children in a secure setting?

The CoPI sessions, hereafter referred to as sessions, took place in a locked classroom within a secure setting. There was a total of ten sessions lasting approximately 45 minutes each. Five sessions involved children and five sessions involved children and staff. The majority of staff were teachers and it was intended that the composition of children and adults would provide a broader understanding of any potential value of CoPI in a secure setting. In particular, the researchers wanted to know if children's self-regulation was affected by the presence of staff 
when doing CoPI. The mixed groups occurred in weeks one to four and also in week ten. The CoPI facilitator was responsible for managing the group during the sessions. The coresearcher had an observational role and did not participate in any of the sessions. At least one member of staff was always present during the children only sessions as dictated by the organisation's health and safety procedures; however, s/he did not participate in the sessions.

Participation in the sessions was open to all children and staff in the secure setting. The researchers initially presented the project to the children informally during their lunch-time break, but the manager was given responsibility for inviting children and staff to the sessions. The intention was to have weekly sessions, though this was not always possible due to various constraints, for example, other events taking place within the secure setting or the availability of staff. Many of the children and staff attended in an unplanned manner, usually in response to a prompt by the manager shortly prior to the session commencing. The majority of children were male and aged between 14-16 years-old. Attendance at the sessions varied between five and eight participants and the frequency of individual attendance ranged from one to eight sessions, though there was a core group of four child participants over the sessions. There were three members of staff with consistent attendance during the mixed sessions. Attendance was affected by a variety of factors; for example, a child was removed from the classroom prior to a session commencing and several children were also prevented from attending by staff due to problematic behaviour in the days prior to a session. Staff attendance depended upon timetables and other factors such as staff illness or urgent matters that demanded attention. The philosophical issues discussed by participants were generally philosophically appropriate and derived from questions generated by the children, for example, 'Is there life after death?', 'Do aliens exist?' and 'What is art?'. 


\section{Data collection}

Data was collected and analysed from the audio recordings of the sessions in an attempt to answer the research questions. From the CoPI rules a list of behaviours were distilled that could be observed during the sessions as a means of examining self-regulation. A matrix was devised with the list of behaviours and the names of participants in each session. The matrices responding to each CoPI session were compared and any differences in coding were reviewed by listening again to the audio recording. This task was done by both researchers as means of enhancing reliability and ensuring robustness of the thematic framework. The researchers coded each of these behaviours when they were demonstrated by participants.

The list of behaviours was then organised under four themes in order to present the findings more clearly. The themes are as follows:

1. Patience and impulsivity - is relevant to the way children control their feelings and emotions.

- wait to be called - participants must wait to be invited to speak by the facilitator and not necessarily in the order they indicate a wish to contribute;

- interruptions on-task - where a participant contributes to the dialogue, but without being called upon to speak;

- interruptions off-task - where a participant speaks without being called upon and on an unrelated topic;

- emotional outbursts - where a participant becomes upset or angry.

2. Making connections - is important to the way children engage with each other when communicating. 
- agreeing - when a participant makes a connection with at least one previous speaker by agreeing with what has been said;

- disagreeing - when a participant makes a connection with at least one previous speaker by disagreeing with what has been said;

- agree and disagree - when a participant makes a connection with at least one previous speaker, but agrees in part with what has been said whilst also disagreeing with some aspect;

- bringing a question - participants were requested to bring at least one philosophical question prior to each session.

3. External control - is necessary where children are unable to follow the rules.

- facilitator enforcing the rules - the facilitator is responsible for imposing the CoPI rules;

- making others follow rules - it is not expected that participants enforce the CoPI rules where another participant fails to adhere to them.

4. Explaining and clarifying - requires reflection, an understanding of the self, perseverance in trying to express one's thinking, and is important in reducing misunderstandings.

- giving an explanation - participants must explain their viewpoint and avoid the use of language (i.e. technical language or jargon) that might serve to exclude others and should not refer to an authority to support their reason-giving, thereby demonstrating their own thinking; 
- facilitator's request for clarification - participants must respond to the facilitator's request for further clarification on a contribution to the dialogue.

Each of the rules were applied against the audio recordings to gauge when they were adhered to or broken by the participants during the sessions. The recordings of the sessions were listened to by both researchers with each coding the sessions independently and compared for reliability. Whilst the coding for most sessions was relatively straightforward, there were a small number of occasions when several people might, for example, interrupt or continue speaking at the same time. On such occasions, only the first instance of rule-breaking was coded. Similarly, sessions one and nine were chaotic and it was not possible to code the transcripts fully, with the latter session being terminated by the facilitator after fifteen minutes due to the dialogue being consistently undermined by the disruptive behaviour of some children. The children attending the sessions were predominately male. Three sessions had no females present and the remainder had either one or two females compared with between three and five males. No females attended more than three sessions compared to one of the males who attended eight sessions. The study adhered to internationally accepted ethical guidelines and was approved by the University Ethics Committee. The CoPI facilitator and participants discussed the project to ensure the participants understood the nature of ethical issues such as confidentiality and anonymity. Written and verbal consent was provided by the Education Manager of the unit as the University's ethical guidelines are clear that with a vulnerable group in this kind of setting, a staff member with management responsibility, acting in loco parentis, may act as gate-keeper where parents cannot be contacted. All staff and children also provided their informed consent.

\section{Results}


The extent to which participants, both children and adults, adhered to the rules during the sessions is analysed in terms of self-regulation. There were a total of 1729 instances when rules were adhered to or broken during the CoPI sessions by children and staff, which are organised within the four themes: patience and impulsivity; making connections; external control; and, explaining and clarifying (Figure 1).

[Table 1 near here].

The frequency of instances for rule-adherence was 1350 for children and 379 for staff. A major factor accounting for this difference arises, as previously noted, from children being present in all ten sessions whereas staff were only present in five. It is also important to recognise that the majority of instances of rule-breaking by children was by boys. The girls contributed much less frequently to the dialogue and their low attendance at the sessions limits any gender analysis on rule-adherence. However, it was clear that girls made fewer interruptions, either on or off-task. When there were interruptions or disruptions, the girls rarely got involved in disruptive behaviours. Contributions by the girls suggest that they remained more focused during the sessions, even if they were speaking on fewer occasions than the boys. When the girls spoke, the boys rarely interrupted. Adherence to the associated behaviours that were distilled from the CoPI rules is considered in relation to each of the four themes.

\section{Patience and impulsivity}

The theme of patience and impulsivity was examined in relation to four associated behaviours: 'Interruptions on-task'; 'Interruptions off-task'; 'Waiting to be called'; and 'Emotional outbursts'. These four associated behaviours were adhered to or broken on 640 
occasions. Instances of adherence to associated behaviours related to patience and impulsivity by children and staff are shown (Figure 2).

[Table 2 near here].

There were 245 interruptions on-task (n 218 children: $n 27$ staff). The interruptions indicate a level of impulsivity where participants made a contribution without waiting to be called by the facilitator. The on-task interruptions varied each week from five to 36 and occurred more frequently with children in the children only sessions (n 142) rather than sessions with staff (n 76). Interruptions on-task related to the dialogue and usually occurred when children were excited and animated by the discussion and arguments. There were 63 interruptions off-task (n 55 children: n 8 staff). Interruptions off-task did not relate to the dialogue and varied each week from zero to 14 . These interruptions were more frequent from children and in the children sessions (n 42) than sessions with staff (n 11). The interruptions off-task usually occurred when children were preoccupied, bored, lacked interest in the dialogue or were distracted by another participant.

The presence of staff appears to be an important factor in reducing the frequency of children's interruptions on-task and interruptions off-task. While this is positive in that the dialogue develops in a more fluent way, it suggests that children often monitored the level of interruptions in response to the presence of staff, rather than a genuine desire to self-regulate in adherence to the CoPI rules. When the interruptions related to the dialogue (interruptions on-task) it was easier for the children to re-engage when directed by the facilitator or other participants. In contrast, off-task interruptions usually required several prompts by the facilitator before an individual re-engaged with the dialogue. The presence of staff might 
therefore be most useful in reducing disruptions where there is a child who has difficulty focusing on the dialogue. Although this might assist in the creation of the dialogue by other participants, the external control created by the presence of staff may not necessarily assist with the development of the children's self-regulation.

Waiting to be called by the facilitator requires children and staff to be patient and recognise the participatory nature of the dialogue. There were 277 instances of 'Waiting to be called' (n 208 children: n 69 staff). During the first session most of the children and staff did not to wait to be called by the facilitator, resulting in a highly fragmented dialogue and unfocused session. As a result, it was impossible to code all of the interruptions (e.g. several people speaking simultaneously) during this session. Only one individual (a child) waited to be called during week one. Adherence to this rule steadily increased by week four and remained relatively constant, with children waiting to be called approximately 20 times each session compared to 13 times for staff. The lower frequency of staff waiting to be called can be accounted for, at least in part, by them allowing the children to engage more frequently in the dialogue or by the children being more experienced in the practice than the staff at this stage. This suggests that children and staff can learn the rule of 'waiting to be called' relatively quickly. Demonstrating the necessary patience when adhering to this specific rule reduced considerably what might be seen as the frenetic and disruptive nature of some sessions.

There were five 'emotional outbursts', all by boys. Two of these outbursts occurred prior to session one commencing and two participants were removed from the room. The three remaining instances involved a child shouting for several brief periods after being provoked. There was no physical violence although there was a degree of intimidation by one child towards another child in one session. This suggests that CoPI creates a forum which is stimulating and whilst there are disruptions, it can generate discussion and debate in a safe and non-threatening way for most children, even for those who openly dislike one another. 


\section{Making connections}

The theme of making connections is conveyed in the associated behaviours: 'Agreeing'; 'Disagreeing'; 'Agreeing and Disagreeing'; and, 'Bringing a Question'. The instances of rule-adherence for making connections are shown (Figure 3).

[Table 3 near here].

In the first session it was apparent that the children were not sufficiently motivated to read a short text or even listen to the facilitator read it, hence, unlike conventional CoPI sessions, the children were asked to think of a question they would like to discuss. For subsequent weeks the children were asked to bring one or more questions for discussion. Usually, only one or two children came to the session with a philosophical question to start a dialogue, although on session nine a child came to the session with four questions. Supporting children to be more proactive in bringing a question might lead to greater ownership of the dialogue and investment in the inquiry.

Agreeing with at least one previous speaker's comment occurred on 114 occasions (n 82 children: $\mathrm{n} 32$ staff) and disagreeing occurred on 145 occasions (n 103 children: n 42 staff). Instances where individuals agreed and also disagreed in part with a contribution happened on 41 occasions (n 27 children: n 14 staff). There were 23 instances when participants brought a question (n 21 children: $\mathrm{n} 2$ staff). Adherence to these associated behaviours suggests that the dialogue provides an opportunity for children to make explicit connections when listening to others. Children and staff tended to disagree more than agree, which shows a willingness to argue when expressing viewpoints. Having to listen and respond to others' 
comments by first agreeing or disagreeing was initially very difficult for some children and staff. By session four, however, participants were more able to make links with previous speakers when contributing to the dialogue.

Making an explicit connection with a speaker is particularly important in conveying respect, and using the phrase 'I agree/disagree with' reduced the emotive nature of some arguments. In new CoPI groups, very often participants find it challenging to relinquish ownership of their contributions, taking time and practice to begin to focus on the dialogue as a whole rather than in terms of personal contributions. Children in the study initially found it challenging when another participant disagreed with them and this was interpreted as their viewpoint being seen as wrong or subject to unfair criticism. In a similar vein, some children interpreted an agreement as a compliment. The same was true for the staff participants. It is reassuring that such personally-focused responses declined with greater involvement in the dialogue. This suggests that the perceived threat from arguing declined and/or the children were more able to regulate feelings, especially when disagreements occurred. Indeed, the children often seemed to enjoy finding disagreements. Disagreement is essential for philosophical dialogue, so this was, in fact, positive. This process of arguing and not feeling threatened by those who disagree might be a particularly important learning experience for the children and the staff who work with them. In the dialogues the children were able to disagree with the staff participants, and vice versa. While there were power dynamics in terms of regulating their behaviour, children and staff were amused by, and enjoyed, disagreeing with each other, and they did this in a way that demonstrated that they had listened to the contributions.

\section{External control}


The theme of external control relates to control imposed by the facilitator or other group members and is identified by the associated behaviours: 'Facilitator Enforcing Rules' and 'Making Others Follow Rules'. The facilitator is responsible for imposing the CoPI rules and when done by participants it is regarded as an instance of rule-breaking, even if it is wellintentioned. Instances of rule-adherence for external control are shown below (Figure 4).

[Table 4 near here].

The facilitator imposed the CoPI rules on 128 occasions (n 103 children: n 25 staff) and participants made each other follow the rules on 17 occasions (n 14 children: n 3 staff). Perhaps not surprisingly, the facilitator imposed the rules more frequently on the children than on the staff. The facilitator imposed the rules on 68 occasions in the children only sessions compared to 35 occasions in the sessions which included staff. This shows that there was less need for the facilitator to impose the rules when staff are present. Rule enforcement by the facilitator varied between six and 20 times during the sessions, with some people not requiring rule enforcement, and it being used on 12 occasions with one child during a session. Children were more likely to make their peers follow the rules when staff were not participating. Of the five sessions with staff, there was only one session where children made others follow the rules and it happened on two occasions, compared to the 12 occasions in the five sessions with children only. It should be noted that rule-breaking need not imply 'bad' behaviour; sometimes participants needed to be reminded of the rules because they were overly excited by the dialogue and therefore were very keen to participate. This becomes a challenge for any participant, but perhaps more so for this particular group of children. Therefore, whilst the presence of staff acts as a form of external control and reduces the 
likelihood of some rule-breaking, it might diminish the opportunities for children to take responsibility for their own behaviour while at the same time imposing external control on their peers.

\section{Explaining and clarifying}

The theme of explaining and clarifying is conveyed in the associated behaviours 'Giving an Explanation' and 'Facilitator's Request for Clarification'. Instances of rule-adherence for explaining and clarifying are shown (Figure 5).

[Table 5 near here].

Giving an explanation occurred on 463 instances (n 348 children: n 115 staff). The frequency of explanations by children increased between week one (n 11) and week five (n 58) and remained relatively constant for the remainder of the sessions. Children gave more explanations when staff were not present. The frequency of staff explanations was consistent across the sessions. The 'Facilitator's request for clarification' occurred on 199 instances (n 160 children: $n 39$ staff) and was necessary when participants needed to provide clarification through an extended contribution or an example to illustrate the point being made. This was in response to the facilitator pushing the dialogue further philosophically rather than the participants not being able to communicate their meaning. Requests by the facilitator for clarification varied each week from 10 to 28 and there were no differences in frequency in the sessions where staff were present. A request for clarification, it should be noted, is not a negative intervention on the part of the facilitator, but what is important is that the participants respond positively to this further probing by the facilitator. There were very few 
instances of participants making 'Reference to Authority' (n 1 child) and using 'Technical Language' (n 5 children: $n 3$ staff). The children and staff were able to express their contributions in everyday language and were able to articulate their justifications without recourse to other sources. Explanations by the children, however, often highlighted very noticeable gaps in their general knowledge on a range of subjects. Improving an adequate knowledge base, therefore, has implications for the way children can contribute to the dialogue in terms of their own ideas and how they might respond to the ideas of others.

\section{Discussion}

Using CoPI in a secure setting is challenging and thought-provoking for the children. Ruleadherence when doing CoPI suggests that highly vulnerable children can increase selfregulation and sustain it for varying periods within a secure setting. CoPI enables these children to engage in philosophical dialogue, which is neither defined nor conceptualised by the facilitator, and can change their own individual ideas based on their creation of the dialogue. Drawing on Baumeister and Vohs' (2004) distinction between self-regulation and self-control, the findings in this study support the dialogue as a goal-directed form of behaviour. Contributing to the dialogue required cognitive, emotional and social understanding of the task and context, which Rueda, Posner, and Rothbart (2007) hold are important for self-regulation. Indeed, in the sessions for the present study, participants were able to collaborate to create meaning, though they need not agree with one another. Moreover, the children were also able to disagree amongst themselves, a clear sign that they were reflecting on what had been said, and something that would likely not have occurred if they were simply being compliant. Self-regulation within the secure setting did not happen because vulnerable children were compliant or wanted to adhere to rules, but rather that the rules enabled them to attain something desirable. While the adherence to certain rules was 
often difficult, the willingness to contribute to the dialogue suggests the children in this secure setting can use self-regulation to argue and debate ideas while working with others to do so. Therefore, it would appear that even in the most controlled environments CoPI can provide opportunities for children to demonstrate self-regulation.

Self-regulation, as evidenced in rule adherence, appeared to vary according to the type of dialogue within CoPI. Mercer's (2000) categories of 'disputational', cumulative' and 'exploratory' talk are useful in understanding the link between language and self-regulation. Disputational talk typically involves disagreements, including assertions and counter assertions. This reflects weak self-regulation which is evident in the increased imposition of rules by the facilitator when there was disruption during the sessions. Cumulative talk develops previous speakers' comments, albeit uncritically, with repetition and simple confirmations of points made, though such repetition did not often happen in the CoPI sessions. The self-regulation to rule adherence is still relatively weak but the facilitator can request clarification to support the participant in taking their point forward. Exploratory talk is characterised by critically engaging in conversations in a constructive manner. Exploratory talk occurred at various times and only required the facilitator to call the next speaker or request clarification, thereby indicating stronger self-regulation to rule adherence. When the exploratory talk involved most or all of the children there was less impulsive and disruptive behaviours. Unlike the exploratory talk described by Mercer (2000), CoPI enables talk to be developed by, for example, exemplification or the use of metaphors, hypothesising or expressing doubt, distinguishing between and exploring terms, and in the essential features of agreement/disagreement with reason-giving (Cassidy and Christie 2013). While Mercer's categories are helpful, the list of behaviours and themes used in this study offered a more appropriate analysis since CoPI dialogue is broader and richer than Mercer's exploratory talk. 
The rich form of exploratory talk in CoPI might offer a valuable means of helping children to develop a better understanding of themselves and their relationships with others in the secure setting. This is clearly crucial to their functioning in secure accommodation and in the community.

Conceptualising self-regulation as something which can be depleted and replenished (Bauer and Baumeister 2011) supports a strengths-based approach (e.g. Saleebey 2002) which is particulary relevant to children in secure care. The children often had to experience some of the CoPI rules being broken on several occasions before understanding their importance to the dialogue. Adherence to CoPI rules requires a conscious thought process in terms of argumentative dialogue, yet certain disruptive and impulsive behaviours might be underpinned by a combination of conscious and unconscious processes. This reflects Baumeister and Vohs (2004) view that self-regulation has to incorporate conscious and unconscious processes, yet there is no way of knowing how children's unconscious processes affected their behaviour in the sessions. The focus on rule adherence was linked to specific behaviours (e.g. interrupting on task) but not the underlying reasons, which might be influenced by these unconscious processes (e.g. attachment issues). Nevertheless, if depleted self-regulation is associated with increased aggression when an individual is provoked (DeWall et al., 2007) an approach which focuses on articulating thinking is likely to be of value. Children in a secure setting who are aware of personal actions such as their ability to engage in argumentative dialogue might benefit from enhanced self-regulation and a greater sense of agency. 
Given that self-regulation is context specific (Khon 2008), there are fundamental issues about control and compliance in secure settings and how it affects opportunities for self-regulation. It was apparent that children's lack of general knowledge or their limited vocabulary stifled some of the contributions. This indicates that whilst children may have the ability to selfregulate, activities need to be established that are suitable and allow them to engage fully in order that they can demonstrate self-regulation. The role of staff in the CoPI sessions is also a limiting factor in that their participation acts as a form of control in reducing disruption, but limits the autonomy of children and their opportunity to self-regulate. The children enjoyed doing CoPI. However, the challenge some of the children experienced in adhering to the rules at certain periods meant the facilitator had to impose the rules much more frequently compared to some groups in a mainstream setting. This is not surprising given the past and contemporary experiences of children in secure accommodation; however, it is important to recognise that the external control imposed by the facilitator only relates to the rules and not to the dialogue. Vassallo's (2015) concerns about schools wanting pupils to be 'managed' rather than 'empowered' may not address the complexity of CoPI in secure accommodation. It may take some children longer to learn to comply with the CoPI rules, but unless they do so it is not possible to engage in the dialogue. In this sense, self-regulation might develop from compliance, but only where the latter can be reduced and/or allow for opportunities in the former. Rather than understanding compliance and self-regulation as mutually exclusive, the findings from this study suggest they can complement each other when working with children in a secure setting.

\section{Policy and practice implications and Conclusion}


Irrespective of the different policy and practices within secure settings across the UK and internationally (Hart 2015), enhancing the self-regulation of children should be recognised as a valuable aspect of child development, and as such, be part of the care and support provided. Yet, self-regulation has warranted little attention in the social work and education literature specific to secure accommodation. Future research could consider if the self-regulation evidenced in the CoPI sessions is transferred into daily life within the secure setting and the wider community. Research which examined rule adherence when doing CoPI with other groups, for example, with children in mainstream schools, would allow for comparisons with the findings from this study in terms of self-regulation. It was not possible to examine changes to self-regulatory strength in the children, yet, this might be a particularly valuable area for future research given the potential benefits not only for those in secure accommodation, but also for highly vulnerable children living in the community.

If self-regulation is to be developed in vulnerable children in secure settings the organisational structures and cultural practices might have to give greater consideration to the ways in which external controls imposed upon children allow sufficient scope to enhance such an important aspect of human development. Enhancing self-regulation in highly vulnerable and volatile children might be perceived as a threat to the external controls necessary to ensure their rehabilitation and protection of the public. Furthermore, encouraging such children to embrace argumentative dialogue might seem counterintuitive, especially in cultures where children are expected to show deference to adults. Such paternalism is, at least in part, located in a belief that self-regulation exists separately or in opposition to external controls in secure settings. Concerns over deviancy training might also be addressed by involving 'high risk' children with those in mainstream schools doing CoPI. Learning to argue using CoPI in a secure setting is based on participation, cooperation and collaboration, which might help to reduce the risk of confrontation and conflictual situations 
escalating out-of-control, especially over relatively trivial matters. Opportunities for practising self-regulation have to be present in the secure setting and as part of the process to support children re-entering the community. Given the poor outcomes experienced by many children leaving secure settings (Moodie 2015), self-regulation might be an important ingredient in the drive to enhancing the quality of their care, and CoPI may be one approach to support this process. 
Figures

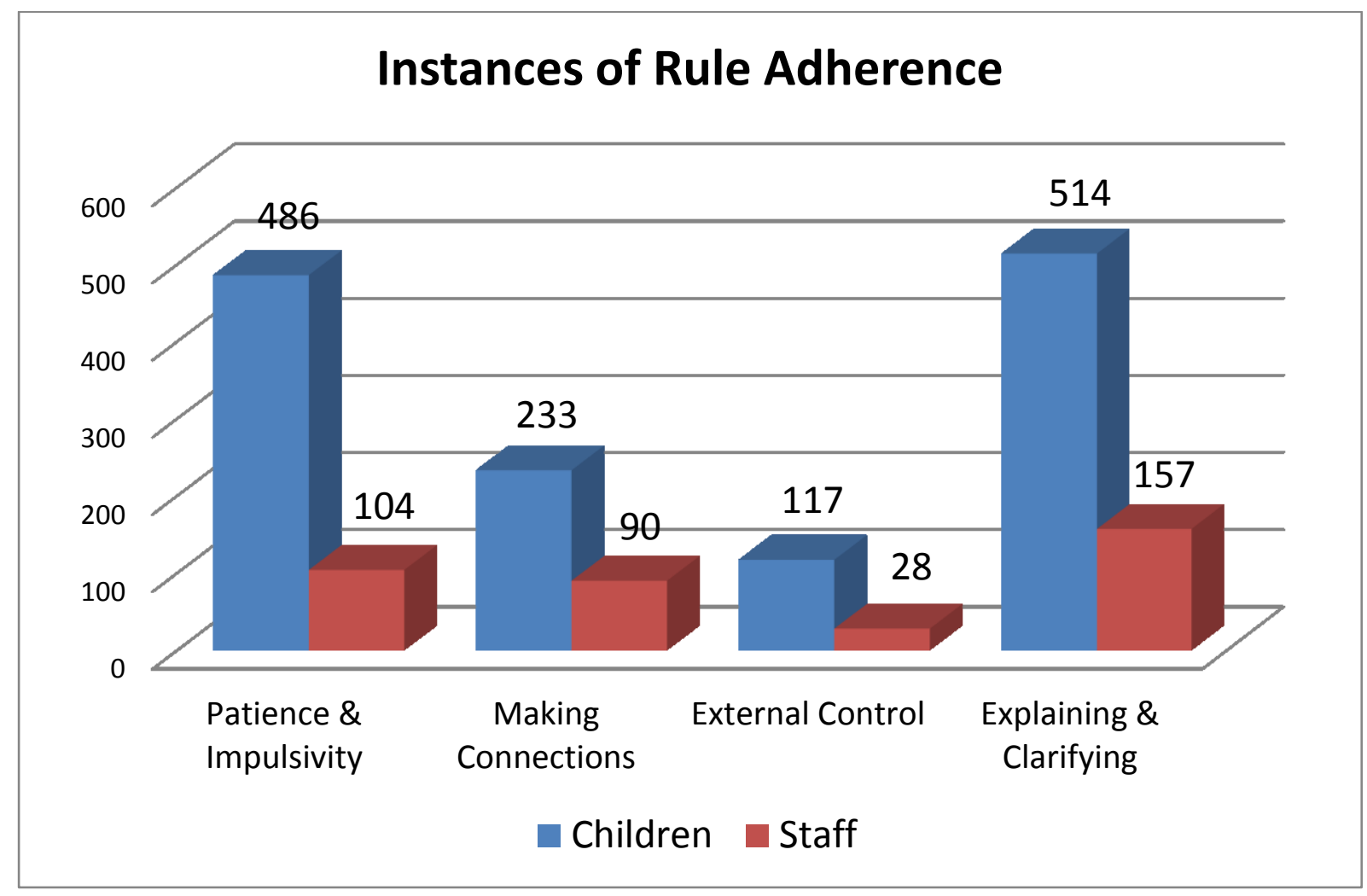

Figure 1: Total instances of rule-adherence across the four themes by children and staff 


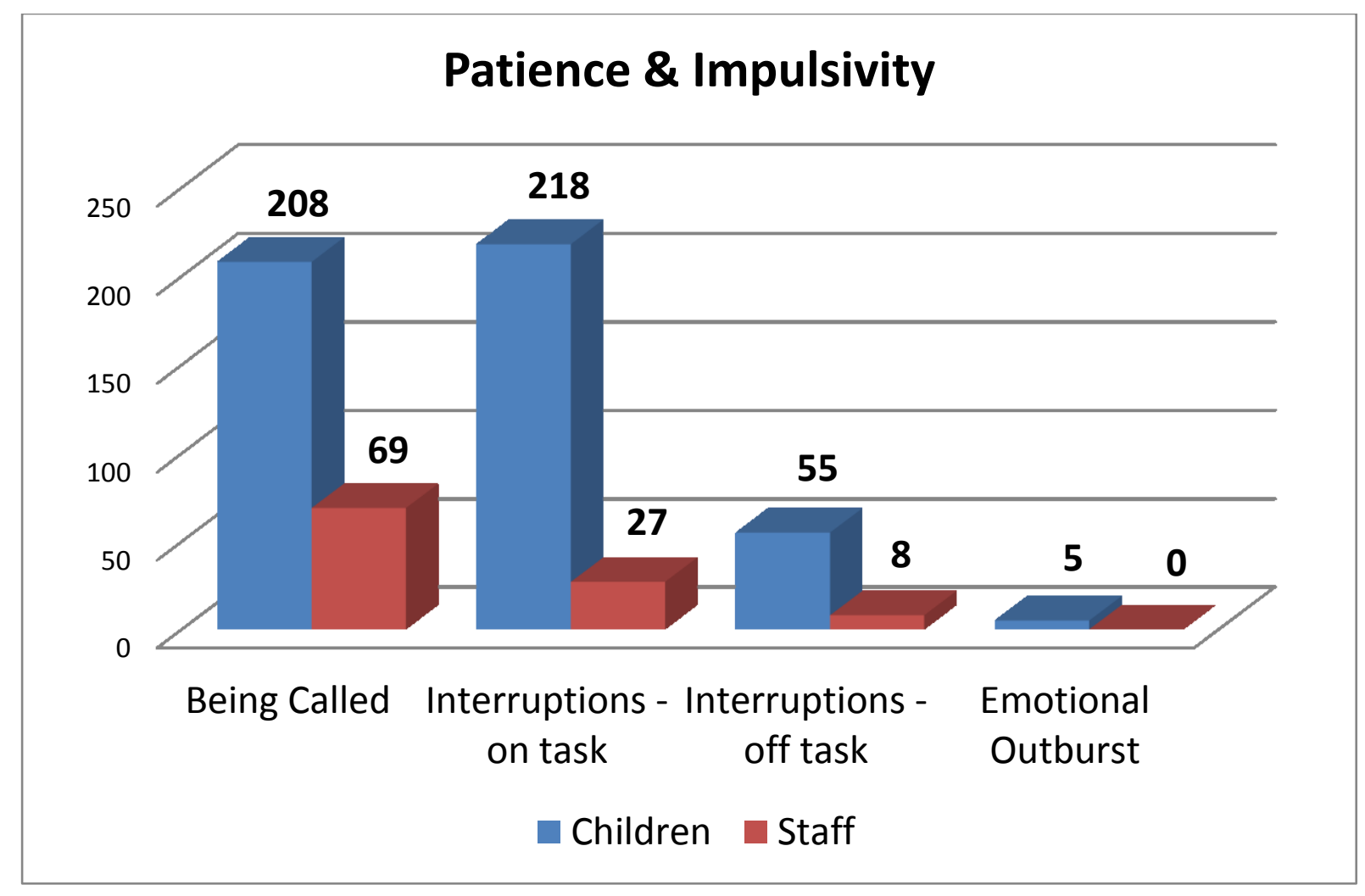

Figure 2 Instances of rule-adherence for patience and impulsivity 


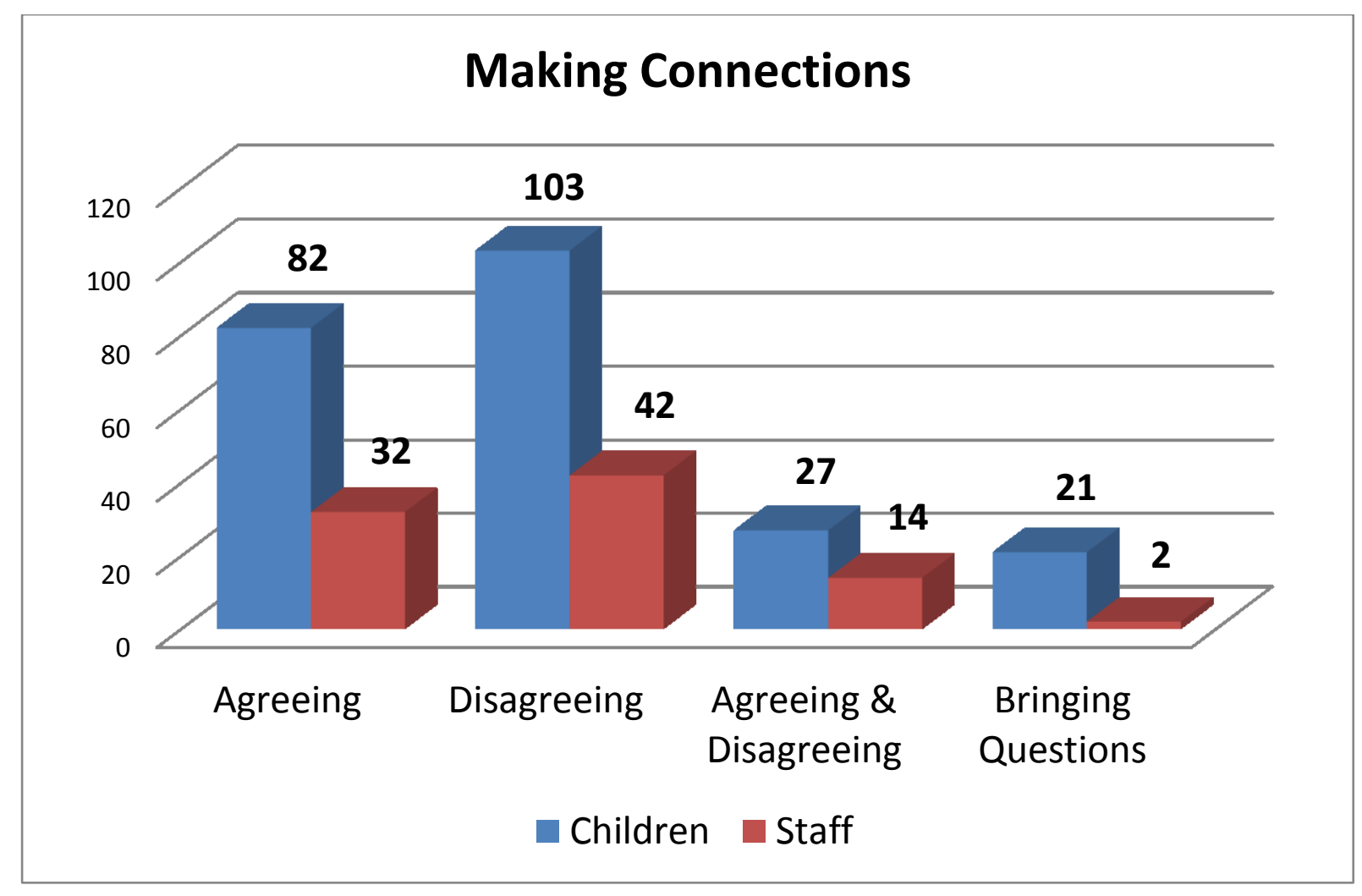

Figure 3 Instances of rule-adherence for making connections 


\section{External Controls}

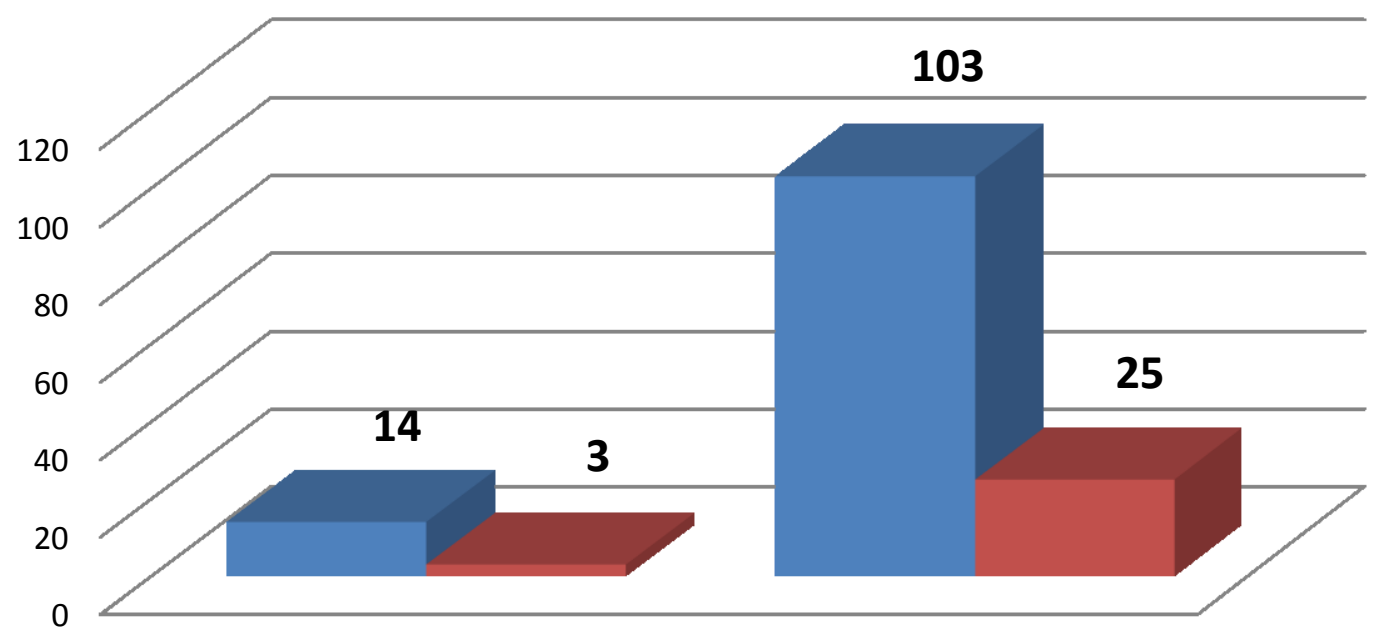

Making Others Follow Facilitator Enforcing Rules Rules

Children Staff

Figure 4 Instances of rule-adherence for external control

\section{Explaining \& Clarifying}

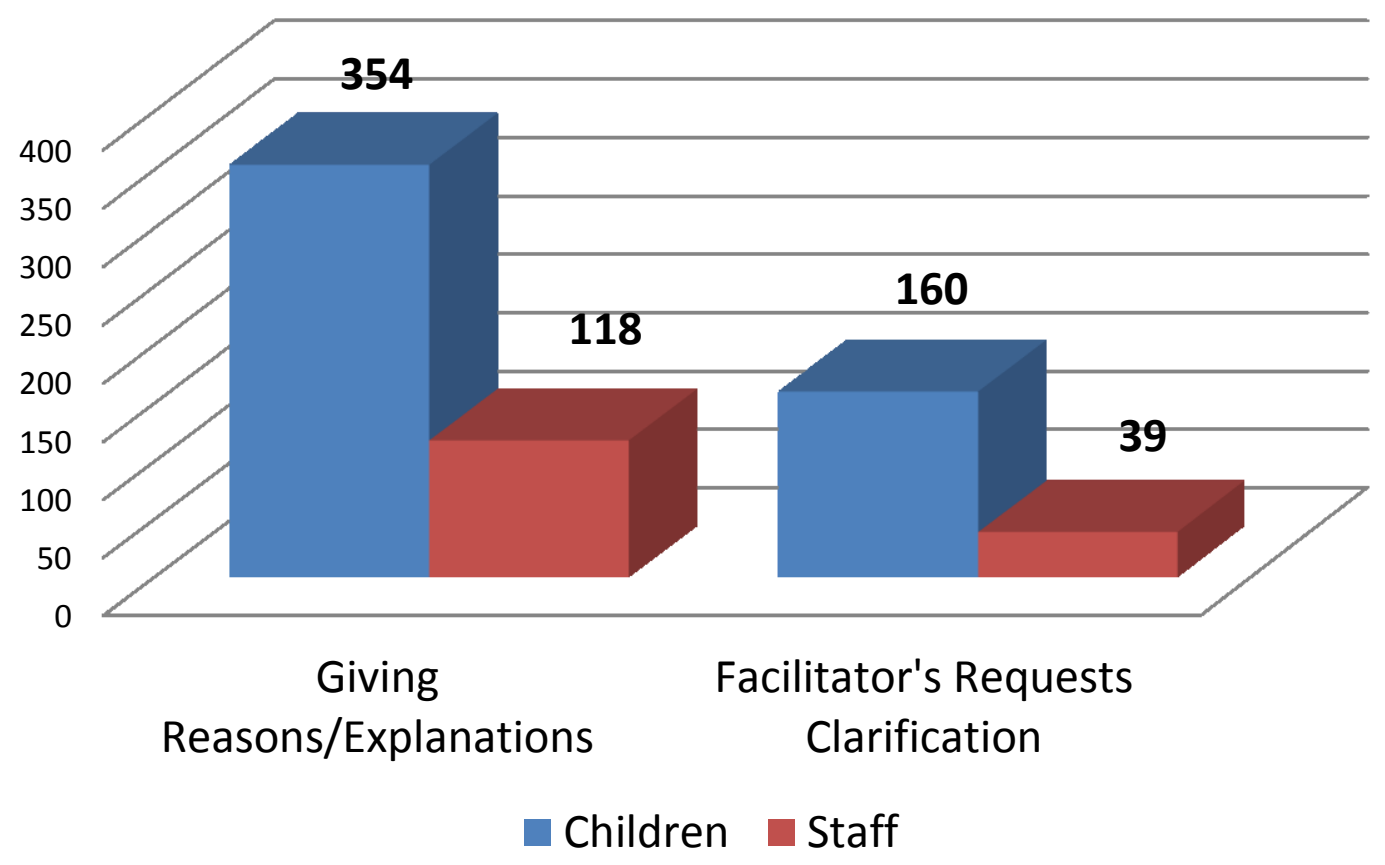


Figure 5 Instances of rule-adherence for explaining and clarifying

\section{Acknowledgement}

The authors would like to thank Prof. Emeritus Donald Christie for his support with this project. 


\section{References}

Bassey, M. 1999. Case Study Research in educational settings. Buckingham: Open University Press.

Bauer, I. M., and R.F. Baumeister. 2011. “Self-regulatory strength.” In Handbook of Selfregulation (second edition): Research, Theory and Applications, edited by K.D. Vohs and R.F. Baumeister, 64-82. New York: Guilford Press.

Baumeister, R.F. and K.D. D. Vohs. eds. 2004. Handbook of Self-regulation: Research, theory and applications. London: Guilford Press.

Boekaerts, M., and L. Corno. 2005. "Self-regulation in the Classroom: A Perspective on Assessment and Intervention." Applied Psychology: An International Review 54 (2): 199-231. doi: 10.1111/j.1464-0597.2005.00205.x.

Bullock, R., M. Little, and S. Millham. 1998. Secure Treatment Outcomes: The Care Careers of Very Difficult Adolescents. Aldershot: Ashgate.

Cassidy, C. 2012. "Questioning children.” Thinking: the Journal of Philosophy for Children, $20(1 / 2): 62-68$.

Cassidy, C. and D. Christie. 2013. "Philosophy with Children: talking, thinking and learning together." Early Child Development and Care 183 (8): 1072-1083. doi: 10.1080/03004430.2013.773509. 
Cassidy, C. and D. Christie. 2014. "Community of Philosophical Inquiry: citizenship in the classroom." Childhood \& Philosophy 10 (19): 33-54.

DeWall, C.N., R.F. Baumeister, T.F. Stillman, and M.T. Gialliot. 2007. "Violence Restrained: Effects of Self-regulation and its Depletion on Aggression.” Journal of Experimental Social Psychology 43 (1): 62-76. doi: org/10.1016/j.jesp.2005.12.005.

Dishion, T., J McCord, and F. Poulin. 1999. "When Interventions Harm: Peer Groups and Problem Behaviour”. American Psychologist, 53 (9): 755-764. doi.org/10.1037/0003066X.54.9.755

Donovan, C. and L. Smolkin. 2002. "Children's Genre Knowledge: An Examination of K-5 Students' Performance on Multiple Tasks Providing Differing Levels of Scaffolding.” Reading Research Quarterly Newark 37 (4): 428-465. DOI: 10.1598/RRQ.37.4.5

Duckworth, K., R. Akerman, A. MacGregor, E. Salter, and J. Vorhaus. 2009. Self-Regulated Learning: A Literature Review. London: Centre for Research on the Wider Benefits of Learning, Institute of Education.

Khon, A. 2008. "Why self-discipline is overrated: The (troubling) theory and practice of control form within". Phi Delta Kappan http://www.alfiekohn.org/article/self-disciplineoverrated/

Hart, D. 2015. Correction or Care? The Use of Custody for Children in Trouble. London: Winston Memorial Trust.

McCall, C. 2009. Transforming Thinking: Philosophical Inquiry in the Primary and Secondary Classroom. London: Routledge. 
Mercer, N. 2000. Words and Minds: How We Use Language to Think Together. London: Routledge.

Miles, M., and A.M. Huberman. 1994. Qualitative data analysis: An expanded sourcebook, 2nd ed. London: Sage.

Moodie, K. 2015. Secure Care in Scotland, a Scoping Study: Developing the Measurement of Outcomes and Sharing Good Practice. Glasgow: Centre for Youth and Criminal Justice.

Morgan, R. 2009. Life in Secure Care. A Report by the Children's Rights Director for England. London: Ofsted.

Mowat, J.G. 2010. "Towards the development of self-regulation in pupils experiencing social and emotional behavioural difficulties (SEBD)". Emotional and Behavioural Difficulties. (15) 3: 189-206. doi.org/10.1080/13632752.2010.497658

Muraven, M., and R.F. Baumeister. 2000. "Self-regulation and Depletion of Limited Resources: Does Self-control Resemble a Muscle?” Psychological Bulletin 126 (2): 247-259. doi: 10.1037//0033-2909.126.2.247.

Roesch-Marsh, A. 2012. “'Out of Control': Making Sense of the Behaviour of Children Referred to Secure Accommodation." British Journal of Social Work 44 (2): 197-213. doi: $\operatorname{org} / 10.1093 / \mathrm{bjsw} / \mathrm{bcs} 102$.

Rueda, M.R., M.I. Posner and Rothbart, M.K. 2007. “Attentional control and self-regulation”. In Handbook of self-regulation: Research, theory and applications, edited by Baumeister, R.F. and K.D Vohs. 283-300. London: The Guilford Press. 
Saleebey, D. 2002. The strengths perspective in social work practice. 3rd edition. Boston: Allyn and Bacon.

Sinclair R. and T. Geraghty. 2008. A Review of the Use of Secure Accommodation in Northern Ireland. London: National Children's Bureau.

Smith, S., A. Daunic, J. Algina, D. Pitts, K. Merrill, M. Cumming, and C. Allen. 2017. "Selfregulation for students with emotional and behavioral disorders: preliminary effects of the I control curriculum". Journal of Emotional and Behavioural Disorders. 25 (3): 143-156. doi.org/10.1177/1063426616661702

Souverein, F.A., G.H.P. Van Der Helm, and G.J.J.M. Stams. 2013. “"Nothing Works” in Secure Residential Youth Care?" Children in Youth Services Review 35 (12): 1941-1945. doi: org/10.1016/j.childyouth.2013.09.010.

Vassallo, S. 2015. "A critical consideration of the alignment between the discourse of selfregulated learning and neoliberalism”. Emotional and Behavioural Difficulties. 29 (1): 82-97. doi.org/10.1207/s15544818ped01014

Yen, C., T.R. Konold, and P.A. McDermott. 2004. "Does Learning Behavior Augment Cognitive Ability as an Indicator of Academic Achievement?' Journal of School Psychology 42 (2): 157-69. doi: org/10.1016/j.jsp.2003.12.001 
